\title{
Synthesis and crystal structure of 6-fluoro-3-hydroxypyrazine-2- carboxamide
}

\author{
Fangyuan Shi ${ }^{1}$, Zongtao $\mathrm{Li}^{2}$, Lingjin Kong ${ }^{2}$, Yuanchao Xie ${ }^{1}$, Tao Zhang ${ }^{2, *}$, Wenfang Xu ${ }^{1, *}$ \\ ${ }^{1}$ Department of Medicinal Chemistry, School of Pharmaceutical Sciences, Shandong University, Ji'nan, Shandong, China; \\ ${ }^{2}$ Shandong Qidu Pharmaceutical Co., Ltd., Zibo, Shandong, China.
}

\begin{abstract}
Summary As a RNA polymerase inhibitor, 6-fluoro-3-hydroxypyrazine-2-carboxamide commercially named favipiravir has been proved to have potent inhibitory activity against RNA viruses in vitro and in vivo. A four-step synthesis of the compound is described in this article, amidation, nitrification, reduction and fluorination with an overall yield of about $8 \%$. In addition, we reported the crystal structure of the title compound. The molecule is almost planar and the intramolecular $\mathrm{O}-\mathrm{H} \cdots \mathrm{O}$ hydrogen bond makes a 6-member ring. In the crystal, molecules are packing governed by both hydrogen bonds and stacking interactions.
\end{abstract}

Keywords: Synthesis, crystal structure, hydrogen bond, $\pi-\pi$ stacking interactions

\section{Introduction}

There is much interest in RNA polymerase inhibitors for their potential contributions in the treatment of the influenza (1-3). One inhibitor, 6-fluoro-3hydroxypyrazine-2-carboxamide named favipiravir was first prepared by Y. Furuta and coworkers (4), and has been proved to have potent inhibitory activity against RNA viruses in vitro and in vivo (5-8). The previously reported synthetic procedure is shown in Scheme 1 involving seven steps starting from 3-aminopyrazine2-carboxylic acid. However, in the ammoniated step, it involves the catalysis of tris(dibenzylideneacetone) dipalladium and (S)-(-)-2,2'-bis(diphenylphosphino)1,1'-binaphthyl (BINAP), which are very expensive. The last step proceeds poorly with a low $(4.3 \%)$ isolated yield, making the overall yield approximately $0.44 \%$. This sythesitc process is hardly suitable for large-scale production. Therefore, in order to improve the yield and reduce the cost, we report a modified procedure that boosts the overall yield over 20 -fold with four steps in this article. We also report the crystal structure of the compund for the first time.

\footnotetext{
*Address correspondence to:

Dr. Wenfang Xu, Department of Medicinal Chemistry, School of Pharmaceutical Sciences, Shandong University, 44, West Culture Road, Ji'nan, Shandong 250012, China.

E-mail:wenfxu@gmail.com
}

\section{Materials and Methods}

\subsection{Materials}

Solvent for anhydrous reaction should be processed before use. ${ }^{1} \mathrm{H}-\mathrm{NMR}$ spectra were determined on a Brucker Avance 300 spectrometer or 600 using tetramethylsilane (TMS) as an internal standard. The solvents for NMR were DMSO-d ${ }^{6}\left(\delta 2.5\right.$ for $\left.{ }^{1} \mathrm{H}\right)$, $\mathrm{CD}_{3} \mathrm{Cl}_{3}\left(\delta 7.3\right.$ for $\left.{ }^{1} \mathrm{H}\right)$. HRMS analysis was provided by Agilent 6520 Q-TOF LC/MS spectrometer (Agilent, Germany). All reactions were monitored by thinlayer chromatography (TLC) on $25.4 \times 76.2 \mathrm{~mm}$ silica gel plates (GF-254). Silica gel used for column chromatography was 200 300 mesh. Melting points were determined on an electrothermal melting point apparatus and were uncorrected.

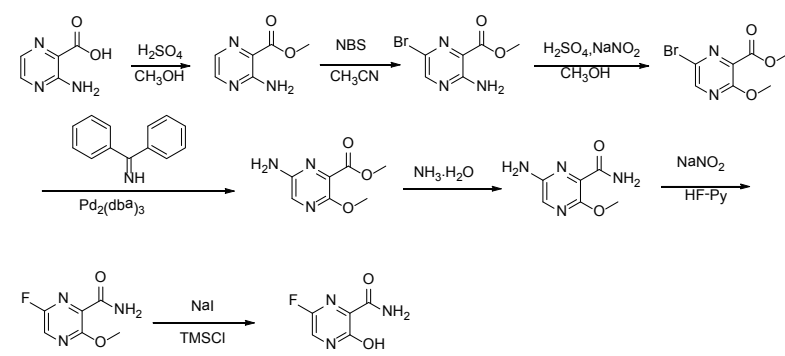

Scheme1. Synthesis of 6-fluoro-3-hydroxypyrazine-2carboxamide reported in the reference. 


\subsection{Synthesis}

\subsubsection{Preparation of 3-hydroxypyrazine-2-carboxamide}

To a suspension of 3-hydroxypyrazine-2-carboxylic acid $(1.4 \mathrm{~g}, 10 \mathrm{mmol})$ in $150 \mathrm{~mL} \mathrm{MeOH}, \mathrm{SOCl}_{2}$ was added dropwise at $40^{\circ} \mathrm{C}$ with magnetic stirring for $6 \mathrm{~h}$ resulting in a bright yellow solution. The reaction was then concentrated to dryness. The residue was dissolved in $50 \mathrm{~mL} 25 \%$ aqueous ammonia and stirred overnight to get a suspension. The precipitate was collected and dried. The solid yellow-brown crude product was recrystallization with $50 \mathrm{~mL}$ water to get the product as pale yellow crystals $(1.1 \mathrm{~g}, 78 \%) . \mathrm{mp}=263-265^{\circ} \mathrm{C}$. ${ }^{1} \mathrm{H}-\mathrm{NMR}$ (300 MHz, DMSO): $\delta 13.34$ (brs, 1H, OH), 8.69 (s, 1H, pyrazine H), 7.93-8.11 (m, 3H, pyrazine $\mathrm{H}, \mathrm{CONH}_{2}$ ). HRMS (ESI): $m / z[\mathrm{M}+\mathrm{H}]^{+}$calcd for $\mathrm{C}_{5} \mathrm{H}_{6} \mathrm{~N}_{3} \mathrm{O}_{2}^{+}$: 140.0460; found: 140.0457 .

\subsubsection{Preparation of 3-hydroxy-6-nitropyrazine-2- carboxamide}

In the solution of 3-hydroxypyrazine-2-carboxamide ( $1.0 \mathrm{~g}, 7 \mathrm{mmol})$ in $6 \mathrm{~mL}$ concentrate sulfuric acid under ice-cooling, potassium nitrate $(1.4 \mathrm{~g}, 14 \mathrm{mmol})$ was added. After stirring at $40^{\circ} \mathrm{C}$ for $4 \mathrm{~h}$, the reaction mixture was poured into $60 \mathrm{~mL}$ water. The product was collected by filtration as yellow solid $(0.62 \mathrm{~g}, 48 \%)$. mp $=250-252{ }^{\circ} \mathrm{C} .{ }^{1} \mathrm{H}-\mathrm{NMR}(600 \mathrm{MHz}, \mathrm{DMSO}): \delta 12.00-$ 15.00 (br, 1H, OH), 8.97 (s, 1H, pyrazine $\mathrm{H}), 8.32$ (s, $\left.1 \mathrm{H}, \mathrm{CONH}_{2}\right), 8.06\left(\mathrm{~s}, 1 \mathrm{H}, \mathrm{CONH}_{2}\right) .{ }^{13} \mathrm{C}-\mathrm{NMR}(75 \mathrm{MHz}$, DMSO): $\delta$ 163.12, 156.49, 142.47, 138.20, 133.81. HRMS (ESI): $m / z[\mathrm{M}+\mathrm{H}]^{+}$calcd for $\mathrm{C}_{5} \mathrm{H}_{5} \mathrm{~N}_{4} \mathrm{O}_{4}^{+}$: 185.0311; found: 185.0304 .

\subsubsection{Preparation of 6-amino-3-hydroxypyrazine-2- carboxamide}

3-Hydroxy-6-nitropyrazine-2-carboxamide (0.6 g, 3.3 $\mathrm{mmol}$ ) and a catalytic amount of raney nickel were suspended in $\mathrm{MeOH}$, then hydrazine hydrate was added dropwise. The resulting solution was refluxed 2 $\mathrm{h}$, cooled, filtered with diatomite, and then $\mathrm{MeOH}$ is evaporated in vacuo to get the crude product as dark brown solid without further purification $(0.4 \mathrm{~g}, 77 \%)$. HRMS (ESI): $m / z[\mathrm{M}+\mathrm{H}]^{+}$calcd for $\mathrm{C}_{5} \mathrm{H}_{7} \mathrm{~N}_{4} \mathrm{O}_{2}{ }^{+}$: 155.0569; found:155.0509.

\subsubsection{Preparation of 6-fluoro-3-hydroxypyrazine-2- carboxamide}

To a solution of 6-amino-3-hydroxypyrazine-2carboxamide $(0.4 \mathrm{~g}, 2.6 \mathrm{mmol})$ in $3 \mathrm{~mL} 70 \% \mathrm{HF}$ pyridine aqueous at $-20^{\circ} \mathrm{C}$ under nitrogen atmosphere, sodium nitrate $(0.35 \mathrm{~g}, 5.2 \mathrm{mmol})$ was added. After stirring $20 \mathrm{~min}$, the solution was warmed to room temperature for another one hour. Then $20 \mathrm{~mL}$ ethyl acetate/water (1:1) were added, after separation of the upper layer, the aqueous phase is extracted with four $20 \mathrm{~mL}$ portions of ethyl acetate. The combined extracts are dried with anhydrous magnesium sulfate and concentrated to dryness to get crude product as oil. The crude product was purified by chromatography column as white solid $(0.12 \mathrm{~g}, 30 \%) . \mathrm{mp}=178-180^{\circ} \mathrm{C}$. ${ }^{1} \mathrm{H}-\mathrm{NMR}$ (600 MHz, DMSO): $\delta 12.34$ (brs, 1H, OH), $8.31(\mathrm{~d}, 1 \mathrm{H}$, pyrazine $\mathrm{H}, J=8.0 \mathrm{~Hz}), 7.44(\mathrm{~s}, 1 \mathrm{H}$, $\left.\mathrm{CONH}_{2}\right), 5.92\left(\mathrm{~s}, 1 \mathrm{H}, \mathrm{CONH}_{2}\right) \cdot{ }^{13} \mathrm{C}-\mathrm{NMR}(75 \mathrm{MHz}$, DMSO): $\delta$ 168.66, 159.69, 153.98, 150.76, 135.68. HRMS (ESI): $m / z[\mathrm{M}+\mathrm{H}]^{+}$calcd for $\mathrm{C}_{5} \mathrm{H}_{5} \mathrm{FN}_{3} \mathrm{O}_{2}{ }^{+}$: 158.0366; found: 158.0360 .

\subsection{Single X-ray crystallography}

6-Fluoro-3-hydroxypyrazine-2-carboxamide ( $0.2 \mathrm{~g}$ ) was dissolved in methanol $(50 \mathrm{~mL})$ at room temperature. Colorless crystals of this compound were obtained through slow evaporation after two weeks. A colorless single crystal with dimension $0.37 \times 0.29 \times 0.27 \mathrm{~mm}^{3}$ was selected for indexing and data collection at 150 Kon aNonius-based Kappa Bruker diffractrometer equipped with a charge-coupled de vice (CCD) area detector and Mo $\mathrm{K} \alpha(\mathrm{k}=0.7107 \AA)$ radiation. The structures were solved by direct methods using the program SHELXS-97 and refined by full-matrix leastsquare refinementon F2 using the program SHELXL-97. All $\mathrm{H}$ atoms were placed in geometrically calculated positions and refined using a riding model with $\mathrm{C}-\mathrm{H}$ $=0.93 \AA$ (for $\mathrm{CH}$ ); $0.86 \AA$ (for $\mathrm{NH}_{2}$ groups) and 0.82 $\AA$ (for $\mathrm{OH}$ ), their isotropic displacement parameters were set to 1.2 times (1.5 times for $\mathrm{OH})$ the equivalent displacement parameter of their parent atoms. Crystal data: $\mathrm{C}_{5} \mathrm{H}_{4} \mathrm{FN}_{3} \mathrm{O}_{2}, \mathrm{Mr}=157.11$, orthorhombic, Pna2 ${ }_{1}$, $\mathrm{Z}=4, \mathrm{a}=9.1106(8), \mathrm{b}=14.7619(14), \mathrm{c}=4.6910(4)$ $\AA, \alpha=\beta=\gamma=90^{\circ}, \mathrm{V}=630.89$ (10) $\AA^{3}, \mathrm{~T}=296 \mathrm{~K}$, $\mathrm{F}(000)=320, \mathrm{u}=0.15 \mathrm{~mm}^{-1}, \mathrm{Dx}=1.654 \mathrm{Mg} \mathrm{m}^{-3}$. 7031 reflections were corrected, 832 unique $\left(\mathrm{R}_{\text {int }}=\right.$ $0.0195) . R_{1}=0.0294, w R_{2}=0.0825$. Further details of the crystallographic data can be found in the supporting information (CCDC deposition number 969968).

\section{Results and Discussion}

The low yield and high cost for the synthesis of favipiravir is attributed to the complicated process and expensive cytalyst in the ammoniated step. 3-Hydroxypyrazine2-carboxylic acid (compound 1) could be purchased or synthsized from 3-aminopyrazine-2-carboxylic acid (9), which is a common intermediate in orgainc synthesis. In our synthetic route, compound $\mathbf{1}$ was first esterified and amidated to give compound $\mathbf{2}$, followed by nitration with potassium nitrate. During the reduction stept, we carried out several different methods. Hydrogen reduction proceeded poorly with a low $(30 \%)$ yield and produced a large number of by-products. Reaction with zinc and 
ammonia produced a large number of brown solid, which were difficult to purity and led to the failure of fluorination. The raney nickel went well with higher (77\%) yield and fewer by-products. In the last fluorination step, it was found that about an hour after the reaction started, the yield decrease with reaction time. If the reaction time exceed 12 $\mathrm{h}$, there would be no product existed. Overall, the target compound was prepared with a yield of about $8 \%$, as shown in Scheme 2.

Slow evaporation of a solution of the title compound in methanol gave single crystals that were suitable for X-ray diffraction. It crystallized in the orthorhombic space group Pna2 ${ }_{1}$. In the title compound, $\mathrm{C}_{5} \mathrm{H}_{4} \mathrm{FN}_{3} \mathrm{O}_{2}$, the molecule is almost planar (r.m.s. deviation for the non- $\mathrm{H}$ atoms $=0.014$ $\AA$ ) and an intramolecular $\mathrm{O}-\mathrm{H} \cdots \mathrm{O}$ hydrogen bond closes a 6-member ring (Figure 1), which can also prevent the ketoenol tautomerism of $\mathrm{C} 3$ position.

In the crystal, the molecules arrange in a prism structure, and are linked into chains by $\mathrm{N}-\mathrm{H} \cdots \mathrm{O}$ hydrogen bonds and $\mathrm{N}-\mathrm{H} \cdots \mathrm{N}$ hydrogen bonds (Figure 2). The characteristics of these bonds are given in Table 1 . The molecules arrange in two nearly vertical $\left(\theta=87.12^{\circ}\right)$ orientations, forming a cavity structure. Each pyrazine ring is both a hydrogen bond donor and acceptor, and these interactions work cooperatively to lock the molecules together. All bond length and angles are in the normal range.

From the crystal structure we find that the neighboring pyrazine ring are nearly-parallel $(\theta=2.81)$, with a vander Waals distance of about $3.23 \AA$. The arrangement of aromatic $(\pi)$ systems predicts that between molecules,

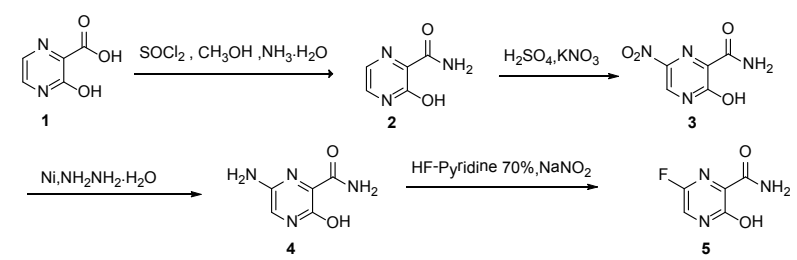

Scheme 2. Synthesis of 6-fluoro-3-hydroxypyrazine-2carboxamide.

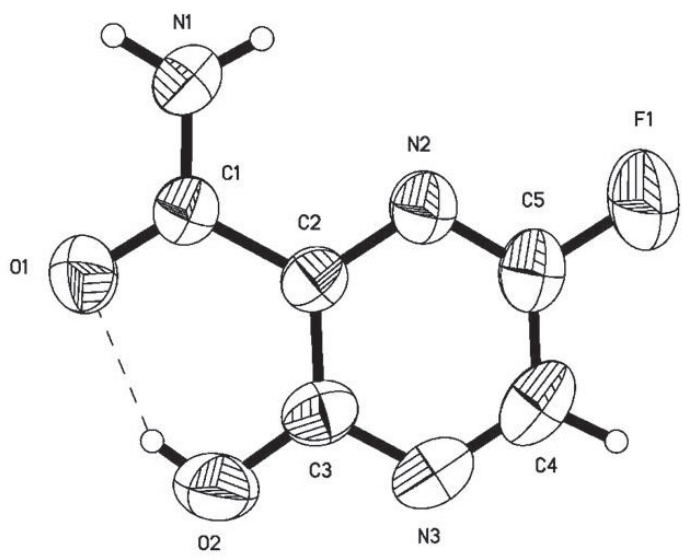

Figure 1. ORTEP plot of the 6-fluoro-3-hydroxypyrazine2-carboxamide. $\pi-\pi$ stacking interactions exist. We note the structure also displays displacement with a distance of about $3.08 \AA$. As we all know, $\pi$ - $\pi$ electron interaction is an important force, which is roughly proportional to the area of $\pi$-overlap. Of course, displacement of $\pi$-systems can diminish the repulsion (10). These characteristics show that the crystal structure is packing governed by both hydrogen bonds and stacking interactions.

\section{Conclusion}

We have presented a new method for the synthesis of 6-fluoro-3-hydroxypyrazine-2-carboxamide, which is more effective and economical relative to the one previously reported. Upon crystallization, we find the molecule is almost planar and exist an intramolecular $\mathrm{O}^{-}$ $\mathrm{H} \cdots \mathrm{O}$ hydrogen bond. Molecules are linked into chains by hydrogen bonds and the neighboring pyrazine ring display $\pi-\pi$ stacking interactions (offset face-to-face). These arrangements show that the crystal structure is packing governed by both hydrogen bonds and stacking interactions, arranging in two nearly vertical orientations and forming a cavity structure.

\section{Acknowledgements}

This work was financially supported by the National Nature Science Foundation of China (No. 21172134), the Doctoral Foundation of Ministry of Education of China (No.20110131110037) and National Scientific and Technological Major Project of Ministry of Science and Technology of China (Grant No. 2011ZX09401-015).

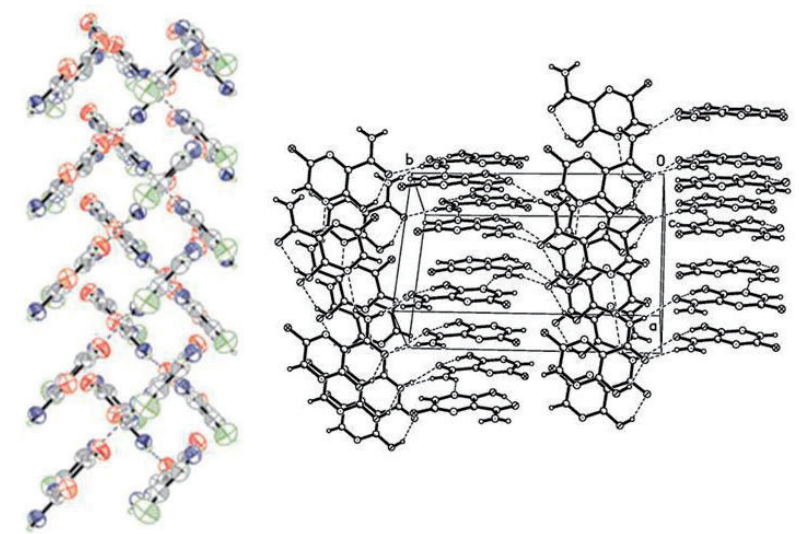

Figure 2. Crystal structure of 6-fluoro-3-hydroxypyrazine2-carboxamide.

Table 1. Hydrogen bonds geometry $\left(\AA,^{\circ}\right)$

\begin{tabular}{lcclc}
\hline$D-\mathrm{H} \cdots A$ & $D-\mathrm{H}$ & $\mathrm{H}-A$ & \multicolumn{1}{c}{$D-A$} & $D-\mathrm{H} \cdots A$ \\
\hline $\mathrm{N} 1-\mathrm{H} 1 \mathrm{~B} \cdots \boldsymbol{N}^{\mathrm{N}}{ }^{\mathrm{i}}$ & 0.86 & 2.34 & $3.000(2)$ & 134 \\
$\mathrm{~N} 1-\mathrm{H} 1 A \cdots \mathrm{O} 1^{\mathrm{ii}}$ & 0.86 & 2.06 & $2.9099(18)$ & 170 \\
$\mathrm{O} 2-\mathrm{H} 2 \cdots \mathrm{O} 1$ & 0.82 & 1.88 & $2.591(2)$ & 144 \\
\hline
\end{tabular}

Symmetry codes: (i) $\mathrm{x}-1 / 2,-\mathrm{y}+1 / 2, \mathrm{z}-1$; (ii) $-\mathrm{x}+1,-\mathrm{y}+1, \mathrm{z}-1 / 2$. 


\section{References}

1. Nistal-Villan E, Garcia-Sastre A. New prospects for the rational design of antivirals. Nat Med. 2009; 15:12531254.

2. Krug RM, Aramini JM. Emerging antiviral targets for influenza A virus. Trends pharmacol Sci. 2009; 30:269-277.

3. Shi F, Xie Y, Shi L, Xu W. Viral RNA polymerase: A promising antiviral target for influenza A virus. Curr Med Chem. 2013; 20:3923-3934.

4. Furuta Y, Takahashi K. Nitrogenous heterocyclic carboxamide derivatives or salts thereof and antiviral agents containing both. WO 00/10569[P]. 2001-04-07.

5. Furuta Y, Gowen BB, Takahashi K, Shiraki K, Smee DF, Barnard DL. Favipiravir (T-705), a novel viral RNA polymerase inhibitor. Antiviral Res. 2013; 100:446-454.

6. Furuta Y, Takahashi K, Shiraki K, Sakamoto K, Smee DF, Barnard DL, Gowen BB, Julander JG, Morrey JD. T-705 (favipiravir) and related compounds: Novel broad- spectrum inhibitors of RNA viral infections. Antiviral Res. 2009; 82:95-102.

7. Furuta Y, Takahashi K, Kuno-Maekawa M, Sangawa H, Uehara S, Kozaki K, Nomura N, Egawa H, Shiraki K. Mechanism of action of T-705 against influenza virus. Antimicrob. Agents Chemother. 2005; 49:981-986.

8. Gowen BB, Wong MH, Jung KH, Sanders AB, Mendenhall M, Bailey KW, Furuta Y, Sidwell RW. In vitro and in vivo activities of T-705 against arenavirus and bunyavirus infections. Antimicrobial Agents Chemother. 2007; 51:31683176.

9. Caldwell JJ, Veillard N, Collins I. Design and synthesis of $2(1 \mathrm{H})$-pyrazinones as inhibitors of protein kinases. Tetradron. 2012; 68:9713-9728.

10. Gło'wka ML, Martynowski D, Kozàowska K. Stacking of six-membered aromatic rings in crystals. J Mol Struct. 1999; 474:81-89.

(Received June 21, 2014; Accepted June 27, 2014) 